\title{
Study on Application of Television Teaching in English Teaching of Students in Non-English Majors
}

\author{
Lisha Xie \\ College of Foreign Languages, Leshan Normal University, Leshan Sichuan, 614000, China
}

Keywords: Non-English majors, Film and television teaching, Applied research.

\begin{abstract}
Compared to English majors, the non-English students learn English mostly from starting their own interests, so how to stimulate non-English majors' interest in learning English teachers would be most concerned about the issue. Television is used in teaching English teaching English multimedia device to play video content in order to win students identity, stimulate students' interest in learning, teaching herein by exploring the advantages of film in a non-English majors teaching, and we explore how to non-English Majors in English Teaching successful introduction of appropriate teaching video.
\end{abstract}

\section{Introduction}

English as a major world-wide language, learn it we live and work have a very positive impact on our educational institutions and teachers attach great importance to the teaching of English in recent years, many English teachers through continuous exploration, and gradually formed a suitable Chinese students learning English mode. With the new curriculum reform and progress of science and technology for non-English majors teaching, many college teachers started by the English movie multimedia devices into the classroom, and actively create a pleasant atmosphere in the classroom to stimulate student interest in learning, reduce the difficulty of learning English. English Television has extensive resources, involving rich in content, reflecting the various aspects of European and American countries language, customs and culture. With European and American movies on the impact of China's film market continues to expand, the students are willing to enjoy like watching movies in English, so English teachers can students' interest in English movies, English movies to use non-English majors teaching English, so not only can expose students to authentic English, but also allows students to enhance English language sense, a better grasp of their own to learn the language and culture, and most importantly, active classroom atmosphere, mobilize the enthusiasm of the students, develop their active learning of English awareness.

\section{Advantages of video resources in English teaching}

Art comes from life than life and film is no exception, whether it is English or Chinese movies are in line with the film's story takes place in a different culture, legend, and real life is that the film has a better sex life more, movie language and lively life, fascinating, is a good teaching resources. At the same time, film education can create a real-life close to the language environment, students watch the video of the process, not only to learn the language, but also can arouse emotional resonance, easier to accept what they have learned. Specifically, the video resources in English Teaching main points:

\section{Promote students' learning interesting}

Interest is the success of the students is a subject whether there is interest in learning, determines the quality of student achievement, have been non-English majors, the English language does not require high level of knowledge, most students do not pay attention, plus English learning boring, students 
are very easy to repel. Currently English teaching English teaching materials is relatively old, most students learn English in order to cope with the CET, the examination is very strong, the focus is teaching vocabulary and grammar exercises memory, listening, reading, etc., in the face of a large number of sea tactical and watching do not understand a word of English, students are very easy to "quit." Therefore, to improve students' interest in learning, stimulate students learning English job desire to become the current university English teachers most need to consider. The film is targeted medicine teaching the subject, it is new and interesting, extremely rich, has a strong storyline dynamic interpretation of life [1], music, speech, and other tasks, it is easy to attract the attention of students, most of the students and the cinema is interested, it is vulnerable to the majority of film and television teaching students of all ages. It allows learning is no longer a burden, but a spirit of enjoyment, students watch a movie, into the story at the same time, unconsciously learned one of the vocabulary, grammar as well as some simple life term for students listening, grammar and writing have a very important role in upgrading.

\section{Animate classroom climate}

Students' English Classroom traditional teaching mode lifeless, sleepy, most students may even a semester of English books is not open before, not to mention hard to learn English. English teachers in the teaching process, but also simply be the word read collar, composition and grammar constitute the vocabulary of the last hair examination paper is to make everyone a lot of practice, a lot of pressure throughout the English class, which for non-English majors It is undoubtedly inappropriate. The film followed the introduction of teaching English class, English class is no longer dead, initiative to improve student learning, naturally active in the classroom atmosphere, not only can enhance the amount of emotional communication between teachers and students, but also to dispel students' English the sense of fear of difficulty, so that students in English class say, willing to learn. And the more different types of film screenings, students can be more comprehensive study to different scenarios, under an atmosphere of dialogue among English, non-English majors to improve English skills.

\section{Build real learning environment}

Learning a language is good, and authentic language environment and learning environment are inseparable, meaning it can help students more accurate understanding of the language, as we learn Chinese, as only involved in real language environment, to be able to formation of language skills in a short period of time. Television Teaching resources mostly from Britain and other countries in all aspects of life, rich in content, diverse subject matter, language, humor, which contains the dialogue of different ages and status of human language style, covering almost all of society, teachers, cultural background and human communication contexts and situations [2]. Students watch the video, you can truly experience life scenes, learn authentic spoken. Face close to the real language environment, students are more able to dedicate myself to learning English in the past, and will subconsciously learning models and movie characters and spoken lines, improve their speaking skills.

\section{Improve students' artistic appreciation}

Film works as a culture, are produced under the control of people out in the concept of culture carrier, the show is the social life of the various phenomena that reflect the cultural connotation of a country and the family name. A movie resources for teaching students through appreciation of the Anglo-American film and television to learn English, not only to improve the ability of students to learn English, but also to develop students' literacy. The current college English teaching, teachers generally pay attention to academic performance, while ignoring the cultivation of students' cultural qualities, just to allow students to learn English and study, but did not really understand the culture and customs of Britain and other countries, so the effect is not learning English high. To improve the cultural quality of college students, to enable students to understand the social and cultural Britain and other countries, and non-English majors in college English teaching video summary of the introduction of teaching is necessary.

\section{Application of video teaching strategies in non-English Majors in English Teaching}


Television has unparalleled advantages in teaching non-English majors of English teaching, at present, the majority of English teachers in colleges and universities are trying to use video teaching to improve student learning English for the interest and curiosity, but did not form a unified system, Some teachers just to follow suit, no careful study, sometimes, the students had completely forgotten the purpose of learning English, but just to watch TV, so as a college English teacher must master the use of non-English majors in English Teaching scale video teaching, allowing students to distinguish between light and heavy, and not just to the students after the screening on the video walk away. This paper argues that the policy is applied in a non-video teaching English Majors in English Teaching can be carried out mainly from the following aspects:

\section{Select appropriate movie resources before class}

Anglo-rich video resources, diverse subject matter, but not any one English movie are able to introduce English teaching, teachers in the choice of video resources, you must first own resources to look at, those mentally sound, video screen clean, and for those of violence, gore, horror and pornography should be filtered. Mentally sound, positive values of the film not only can help students improve their English, but also helps students to establish a correct outlook on life values, to stimulate students' morale, cultivate sentiments of students, learning the entrepreneurial spirit, make it a useful person to society. For example, "The Pursuit of Happiness" film, the father tells Chris Garner with all the savings to buy high-tech treatment, but no hospital is willing to accept that he cannot give his wife and children trying to run out of a happy living environment, and ultimately chose to leave his wife home, leaving his son had each other, and finally the father of the film for the chance to invest in a stock company practice, although there is no reward, but there are fifty percent chances of success in his look, the son is his strength, he is convinced that as long as they work hard, even suffered supercilious, happiness will one day come. This movie tells us not give up in the face of adversity, success will one day come upon you. It can guide students through the proper effort to change their clear and inspire students to distribute up. In addition, teachers should have a conscious choice a number of film and television play different themes, war, youth, animation, so that students from multiple angles and emotions to face different locales. But regardless of how teachers select video as a teaching resource, the most important principle is a need to meet the English proficiency of students and teaching content, select the voice pure, beautiful tone of the film for students to appreciate [3], otherwise departing from the original intention of Television Teaching affecting teaching achievements.

\section{Teacher-student interaction in the class}

Television only as to the teaching of English Majors in English Teaching a way that it is for the English teaching and service, teachers in the teaching process is not available cart before the horse, but according to class time and course content appropriate to the student body combined with teaching content, on a simple interactive movie. For example, before the show can ask students if you want to read the movies, you can let the students read a simple description of the film; the students have not seen the drafts can check in advance the information on the network, familiar with the movie. In the screening process, due to time constraints, teachers can intercept several of the most exciting film clips were broadcast, random play mode can also be changed, such as the first pass screening with no subtitles, dictation ability of students to exercise, the second time show with character, testing students correctly understand the meaning of the film. In the screening process, you encounter new words, teachers can pause for students to explain the meaning of new words and usage, so that students learn in a timely manner to understand and master new words. In addition to playing video, music teachers can also appear in the movie to play, let alone the students understand the lyrics, and then publish the correct answer, the exercise students' English listening ability.

\section{Consolidate knowledge after class}

With the reform of the new curriculum, the sea tactical no longer the only way to improve academic performance, but it is undeniable that the consolidation exercise can still help students better understand and master the knowledge, for learning English, non-English majors students also need to dictation in earnest after-school textbook, cloze, essay writing and translation exercises [4], to further 
reinforce learning in the classroom of new knowledge. For film and television teaching, if students are not well understood in the classroom to play video content that can be viewed while the teacher after class to copy resources, and try one of the wonderful contrast to the roles and imitate. After class, the teacher can ask students to write a book review videos, allow students to express their own viewing experience from the depth of thought and language organization, further training students' vocabulary and writing skills.

In our current English teaching, students often do not speak and write, so university teachers should focus on students self-learning ability [5], to create a good learning environment for students in the class, such as English Corner organization, let non-English majors and students try to communicate in English, spoken language training ability to encourage students to speak up, develop students' communicative competence in English to help students overcome the English language "afraid of difficulties" psychological. Only English learning throughout the class after class activities, and then it is able to more effectively promote students' English proficiency.

\section{Conclusions}

In summary, the introduction of non-English majors in English teaching video teaching to improve the quality of teaching English proficiency of students and teachers have a very important role. Video teaching so that sound and image integration, language and situations combined, so not only can stimulate students' interest in learning, active classroom atmosphere, but also to further the students to create a real learning situation, students of literacy. In the actual classroom teaching, teachers should be careful to select the movie based on classroom content and resources of actual English proficiency of students, not only for students' English proficiency is responsible, but also for the students to establish healthy and positive values, so that students can learn in the film more books to school less than knowledge. In the process of playing videos, teachers and students should feel free to interact, to enable students to learn English as their first goal, a conscious exercise students' English listening and speaking ability, enhance the feelings of teachers and students, so that more students like English, like English lesson. After class, the teacher requires students to complete the relevant contact on the outside of the textbook, students can also organize effective activities in English, so that students come out from the film, in real life, daring to speak English, urging students English writing, listening, speaking, reading and writing to enhance the comprehensive English proficiency of students in four areas. Therefore, this new film and television teaching English teaching mode for non-English majors to learn English has a great role in promoting the majority of English teachers in colleges and universities to actively introduce this teaching model, as soon as possible to improve students' English proficiency.

\section{References}

[1] Ma Xinyan. Television Teaching in Non - English Majors in English Teaching. Curriculum and Educational Studies,2013,31:104-105.

[2] Zuo Yanlin. English film in non-English majors heard teaching. Movie Review,2008,10:72+77.

[3] Chen Wan, Wang Xiaoling. College English video teaching theory and practice. Journal of Hebei University of Technology (Social sciences edition),2009,04:180-181+184.

[4] Wu Wenliang. On the British and American film appreciation and cultural awareness of College Students. Film literature,2011,16:159-160.

[5] Xia Hongying. English use the original movie resources for college English teaching. Huaxia Medicine, 2014,01:172-173. 